\title{
New single crystal superalloys - overview and update
}

\author{
Jacqueline Wahl ${ }^{\mathrm{a}}$ and Ken Harris \\ Cannon-Muskegon Corporation [A PCC Company], 2875 Lincoln St, Muskegon, MI 49441, USA
}

\begin{abstract}
Single crystal (SX) superalloys have wide application in the high pressure turbine section of aero and industrial gas turbine engines due to the unique combination of properties and performance. Since introduction of single crystal casting technology, SX alloy development has focused on increased temperature capability, and major improvements in alloy performance have been associated with the introduction of new alloying elements, including rhenium $(\mathrm{Re})$ and ruthenium $(\mathrm{Ru}) .3 \%$ Re-containing second generation alloys have seen the greatest market utilization and have become the benchmark alloys for comparing new alloy developments. However, Re and $\mathrm{Ru}$ are rare elements with limited production/availability and corresponding high costs. This has resulted in significant escalation of SX alloy costs, resulting in much interest in the development of improved SX superalloys with lower Re or no Re content compared to second generation alloys. Cannon-Muskegon ${ }^{\circledR}$ has developed two new SX superalloys: $1.5 \%$ Re CMSX ${ }^{\circledR}-8$ alloy and $\mathrm{CMSX}^{\circledR}-7$ alloy, which contains no Re, as alternatives to first and second generation alloys for applications which require slightly less ultra high temperature capability compared to current alloys. This paper provides an overview of development and characterization of these SX alloys, including an update on recent results.
\end{abstract}

\section{Introduction}

Since the introduction of single crystal (SX) casting technology in the late 1970's, single crystal alloy development has generally focused on increasing temperature capability. Major improvements in alloy performance have been associated with the introduction of new alloying elements, including rhenium $(\mathrm{Re})$ and ruthenium $(\mathrm{Ru})$ $[1,2]$. Rhenium, in particular, has been widely used in advanced single crystal superalloys for turbine blade, vane and seal segments due to its potent effect in slowing diffusion, creep deformation and fatigue crack initiation under high temperature operating conditions [3]. High temperature creep resistance and fatigue properties are directly related to the useful service life of gas turbine components and turbine engine performance such as power output, fuel burn and carbon dioxide emissions. Consequently, 3\% Re-containing "second generation" SX alloys, such as CMSX-4 ${ }^{\circledR}$, PWA 1484 and Rene' N5 have seen the greatest market utilization and have become the benchmark alloys for comparing new alloy developments.

However, Re is a rare element by-product from mining and processing copper and copper/molybdenum; $\mathrm{Ru}$ is a precious metal by-product principally from platinum production. As a result, both elements have limited market availability and extremely high cost which has resulted in significant escalation of SX alloy costs. In addition, Re use creates a supply chain risk economically and

\footnotetext{
${ }^{a}$ Corresponding author: jwahl@canmkg.com

$\mathrm{CMSX}-4^{\circledR}, \mathrm{CMSX}^{-2^{\circledR}}, \mathrm{CMSX}^{\circledR} 3^{\circledR}, \mathrm{CMSX}^{\circledR}$ and CannonMuskegon ${ }^{\circledR}$ are registered trademarks of Cannon-Muskegon Corporation.
}

Table 1. CMSX-8 alloy nominal chemistry.

\begin{tabular}{|c|c|c|c|}
\hline Element & $\mathrm{Wt} \%$ & Element & $\mathrm{Wt} \%$ \\
\hline $\mathrm{Cr}$ & 5.4 & $\mathrm{Re}$ & 1.5 \\
\hline $\mathrm{Co}$ & 10 & $\mathrm{Al}$ & 5.7 \\
\hline $\mathrm{Mo}$ & 0.6 & $\mathrm{Ti}$ & 0.7 \\
\hline $\mathrm{Ta}$ & 8 & $\mathrm{Hf}$ & 0.1 \\
\hline $\mathrm{W}$ & 8 & $\mathrm{Ni}$ & Balance \\
\hline
\end{tabular}

strategically. Consequently, industry interest in alternative SX superalloys with reduced Re content has emerged.

As initially presented at SUPERALLOYS 2012 [4], Cannon-Muskegon has developed two new proprietary SX superalloys: CMSX ${ }^{\mathbb{B}}-8$ alloy containing $1.5 \% \mathrm{Re}$ is an alternative to $2^{\text {nd }}$ generation alloys for applications with slightly lower maximum temperature requirements and CMSX $^{\circledR}-7$ alloy, which contains no Re, with improved properties over $1^{\text {st }}$ generation alloys, such as CMSX-2/3 ${ }^{\mathbb{B}}$ and PWA 1480.

\section{CMSX-8 alloy}

The nominal chemistry of CMSX-8 alloy is shown in Table 1. Development goals were to target $2^{\text {nd }}$ generation SX alloy properties, castability and stability with significantly reduced Re content. Refractory elements ( Ta, W, Re, Mo) were balanced to achieve creep-rupture properties and balanced with $\mathrm{Cr}$ and $\mathrm{Co}$ content to ensure phase stability. The high Ta content is designed for SX castability and freedom from freckling defects. Al, Ti and Ta content will produce $\sim 70 \%$ volume fraction $\gamma^{\prime}$ phase, while high $\mathrm{Al}$, low Mo plus a small $\mathrm{Hf}$ addition

This is an Open Access article distributed under the terms of the Creative Commons Attribution License 4.0, which permits unrestricted use, distribution, and reproduction in any medium, provided the original work is properly cited. 

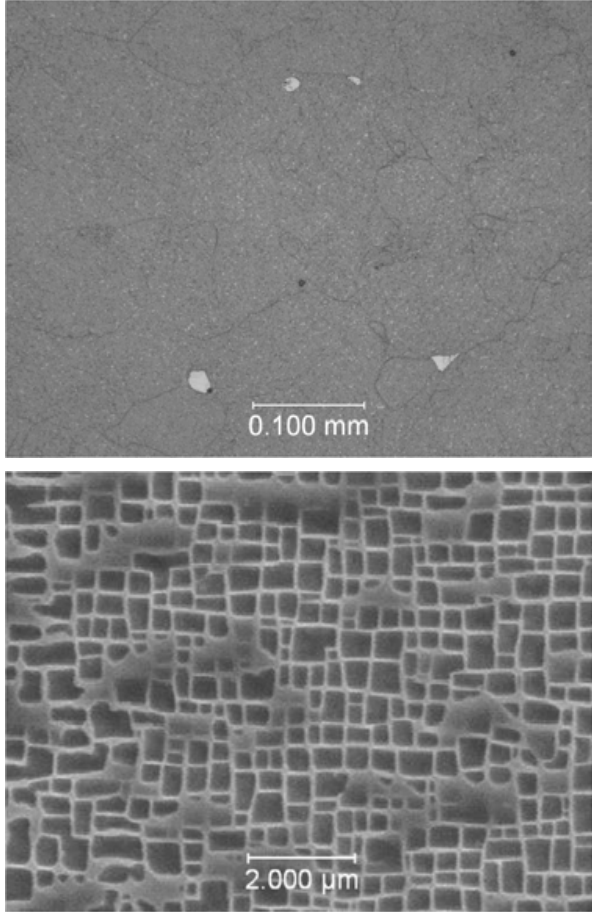

Figure 1. CMSX-8 casting microstructure following solution + double age heat treatment.

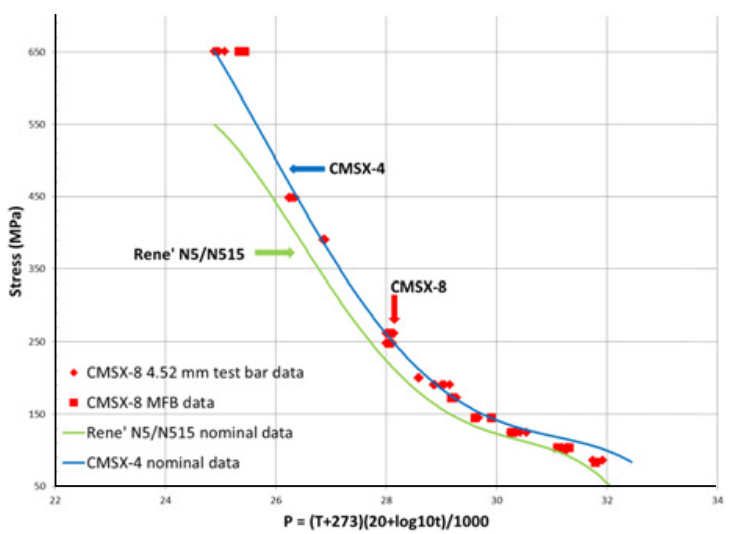

Figure 2. Larson-Miller rupture life of CMSX-8 vs. CMSX-4 and Rene' N5/N515.

improves bare alloy oxidation resistance and coating adherence. The density of CMSX-8 alloy is $\sim 8.85 \mathrm{~g} / \mathrm{cm}^{3}$. DSC solidus and liquidus temperatures are $1338^{\circ} \mathrm{C}$ and $1389^{\circ} \mathrm{C}$, respectively.

Development of a multi-step solution heat treatment and double age cycle produces complete $\gamma^{\prime}$ solutioning with some remnant $\gamma / \gamma^{\prime}$ eutectic, no incipient melting and $\sim 0.45 \mu \mathrm{m}$ average cubic aligned $\gamma^{\prime}$ phase indicating appropriate $\gamma / \gamma^{\prime}$ mismatch and interfacial chemistry (Fig. 1).

\subsection{Mechanical properties}

Extensive mechanical property testing has been conducted on CMSX-8 alloy, including creep- and stress-rupture testing over a range of temperature/stress conditions. As shown in Larson-Miller rupture life curves, CMSX-8 alloy has similar creep properties to CMSX-4 alloy to

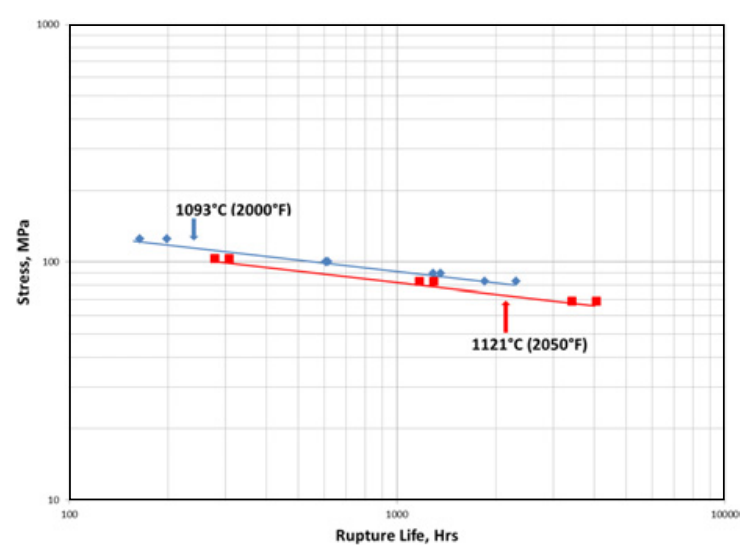

Figure 3. CMSX-8 alloy stress-rupture curves.
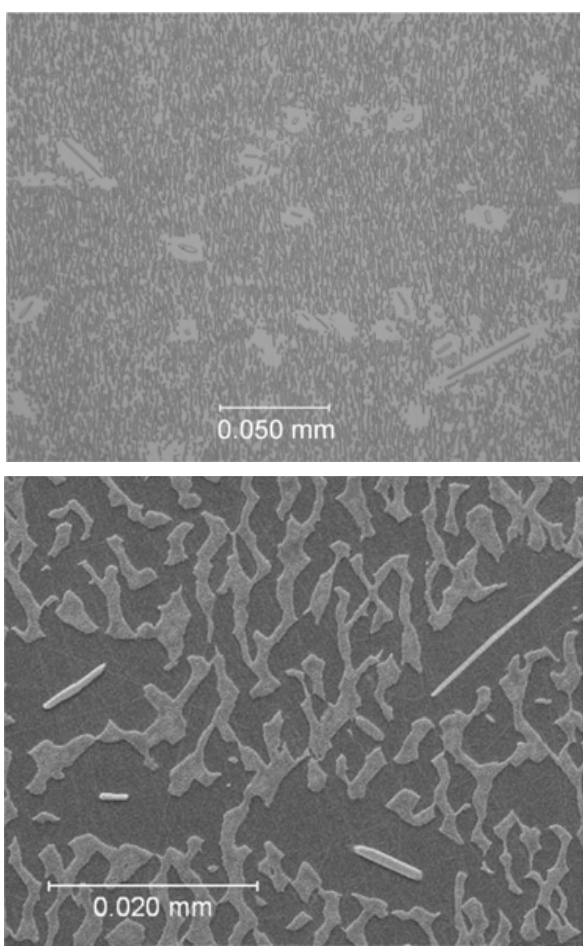

Figure 4. CMSX-8 microstructure following 4060 hours stressrupture testing at $1121^{\circ} \mathrm{C}$.

approximately $1038^{\circ} \mathrm{C}$ and exceeds published properties for Rene' N5 and Rene' N515 alloys over a range of test conditions (Fig. 2) [1,5,6]. Stress-rupture curves at $1093^{\circ} \mathrm{C}$ and $1121^{\circ} \mathrm{C}$ are linear indicating no fall-off in properties due to phase stability issues (Fig. 3). This is confirmed by post-test metallography after 4060 hours at $1121^{\circ} \mathrm{C}$ which shows small isolated TCP phase formation, but not associated with creep cracking or significant dealloying (Fig. 4).

Fatigue properties are typically design-specific to each engine manufacturer; however, limited strain-controlled low cycle fatigue (LCF) testing has been conducted in conjunction with two OEMs for comparison to commercial SX alloy applications. Typical S-N curves for R-ratios of 0 and -1 are shown in Figs. 5-7. Based on discussions with the OEM, results obtained are excellent compared to CMSX-4 alloy. 


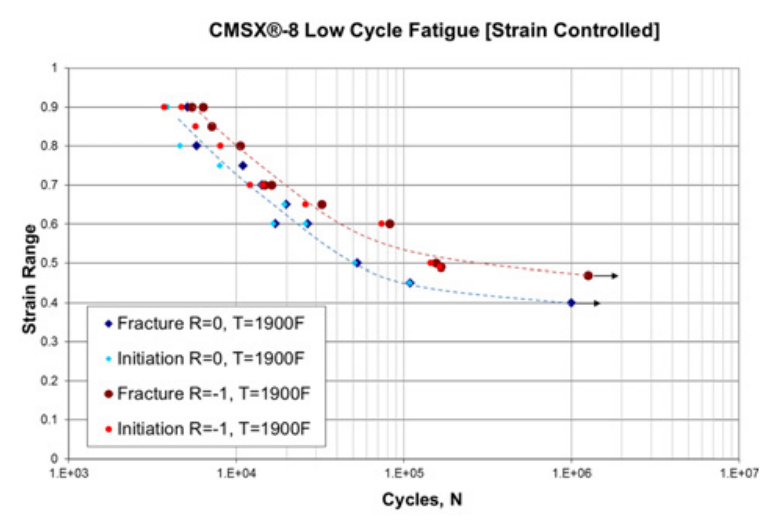

Figure 5. CMSX-8 $1038^{\circ} \mathrm{C}$ LCF data.

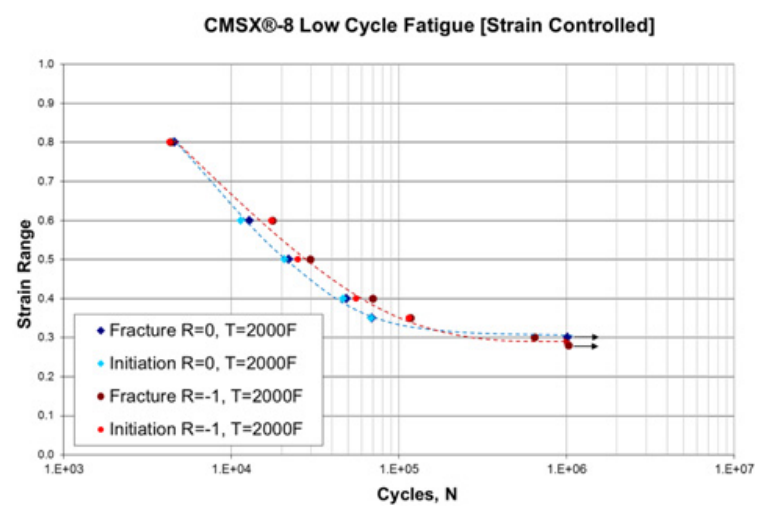

Figure 6. CMSX-8 $1093^{\circ} \mathrm{C}$ LCF data.

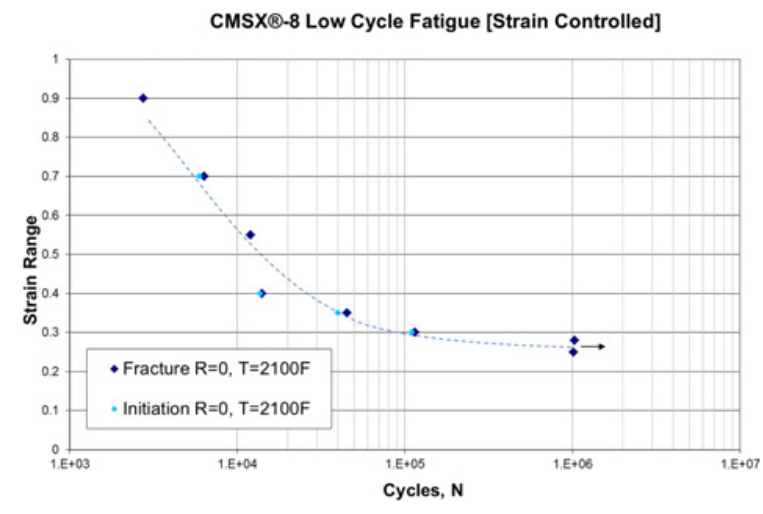

Figure 7. HIP'ed CMSX-8 $1150^{\circ} \mathrm{C}$ LCF data.

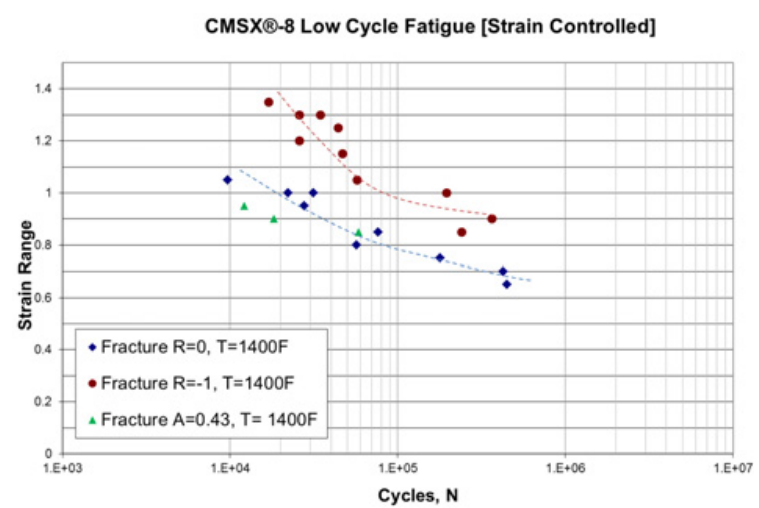

Figure 8. CMSX $-8760^{\circ} \mathrm{C} \mathrm{LCF}$ data.

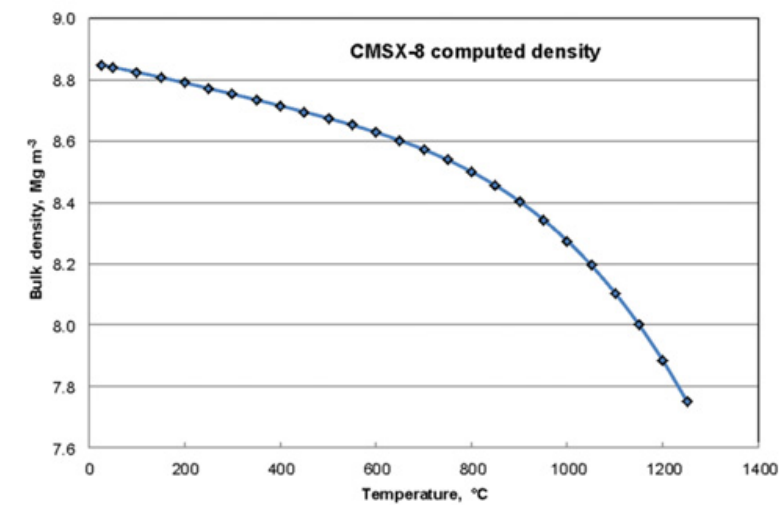

Figure 9. CMSX-8 density vs. Temperature.

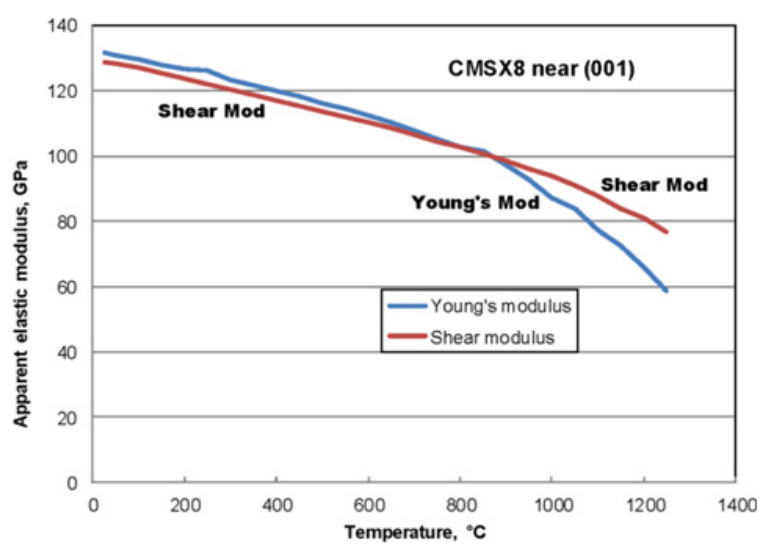

Figure 10. Young's and shear modulus vs. Temperature.

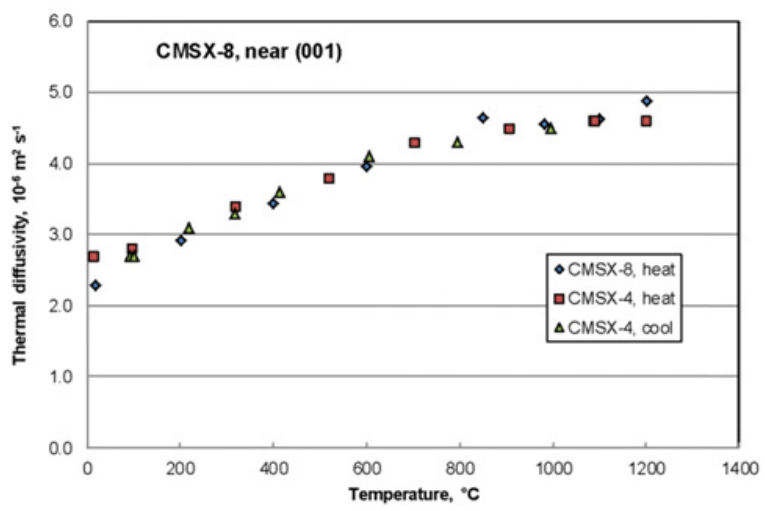

Figure 11. Thermal diffusivity vs. Temperature.

Similar testing was conducted at $760^{\circ} \mathrm{C}$, with R-ratios of $-1,0$ and 0.4 , approximating the temperature/stress regime for the blade shank area for commercial turbine blade applications (Fig. 8). This data indicated favourable performance compared to the current $1^{\text {st }}$ generation (nonRe-bearing) SX alloy.

\subsection{Physical properties}

CMSX-8 physical properties have been characterized in collaboration with the National Physical Laboratory in the United Kingdom. Density, Young's and shear moduli, thermal diffusivity and thermal conductivity as a function 


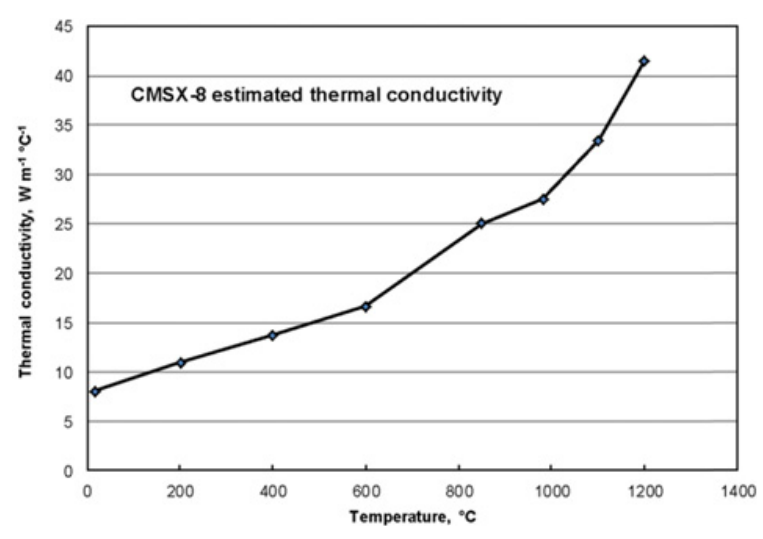

Figure 12. Thermal conductivity vs. temperature.

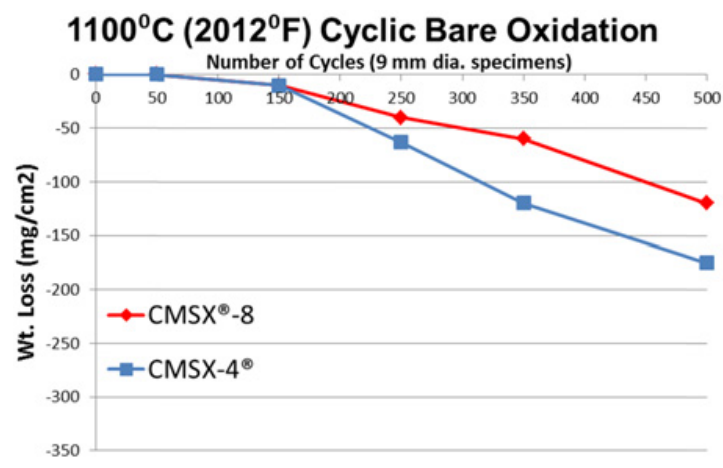

Figure 13. CMSX-8 vs. CMSX-4 bare oxidation comparison.

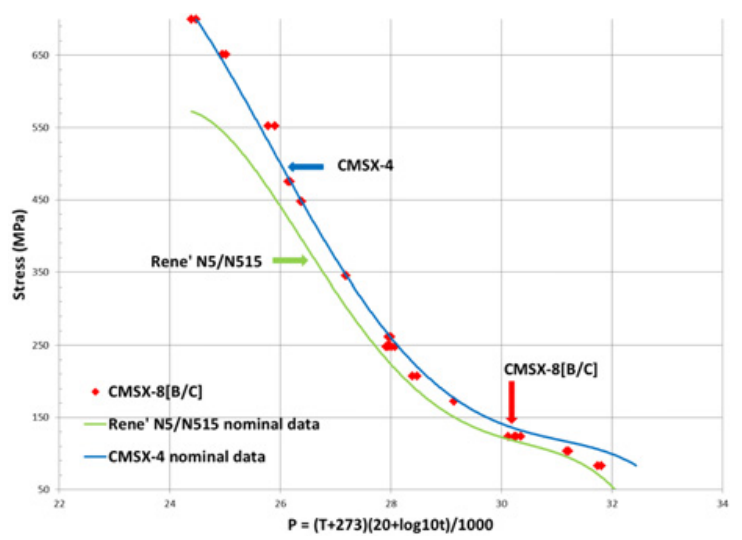

Figure 14. Larson-Miller rupture life of CMSX-8[B/C] alloy vs. CMSX-4 and Rene' N5/N515.

of temperature are shown in Figs. 9-12. Initial cyclic bare oxidation test results, conducted by Turbomeca at $1100{ }^{\circ} \mathrm{C}$ are shown in Fig. 13.

\subsection{Alloy modifications and enhancements}

The addition of grain boundary strengthening elements carbon and boron have been shown to improve low angle boundary (LAB) defect accomodation for large and/or difficult to cast SX components such as industrial gas turbine blades and vanes [7]. Assessment of the modified alloy CMSX-8[B/C] is well underway and show creeprupture properties consistent with the standard CMSX-8 database (Fig. 14).
Table 2. CMSX-7 alloy nominal chemistry.

\begin{tabular}{|c|c|c|c|}
\hline Element & $\mathrm{Wt} \%$ & Element & $\mathrm{Wt} \%$ \\
\hline $\mathrm{Cr}$ & 6 & $\mathrm{Re}$ & - \\
\hline $\mathrm{Co}$ & 10 & $\mathrm{Al}$ & 5.7 \\
\hline $\mathrm{Mo}$ & 0.6 & $\mathrm{Ti}$ & 0.8 \\
\hline $\mathrm{Ta}$ & 9 & $\mathrm{Hf}$ & 0.2 \\
\hline $\mathrm{W}$ & 9 & $\mathrm{Ni}$ & Balance \\
\hline
\end{tabular}

Proprietary Cannon-Muskegon virgin raw material and vacuum induction melting technology is also available to produce CMSX-8(SLS) and CMSX-8[B/C](SLS) alloys with extremely low sulphur content. These alloys demonstrate the same alloys properties with improved environmental properties (oxidation/hot corrosion) for enhanced performance and TBC/coating life.

\subsection{Pre-production experience}

Pre-production casting and design database property assessment is in process at two OEM's and multiple major SX casting foundries for both CMSX-8 and CMSX-8[B/C $]$ alloys. The CMSX-8[B/C] work involves very large SX IGT $1^{\text {st }}$ stage blades with mould pour weights of approximately $55 \mathrm{kgs}$. This work confirms the excellent castability/yield results, mechanical and physical properties established during alloy development; the heat qualification properties exceed preliminary specification stress-rupture requirements by more than $2 \mathrm{x}$.

\section{CMSX-7 alloy}

In a parallel effort, development of a new non-Re-bearing alloy with improved mechanical properties compared to existing $1^{\text {st }}$ generation alloys was undertaken and produced CMSX-7 alloy (Table 2). This work utilized $30+$ years industry experience and understanding of SX casting alloys and technology to further optimize strength, heat treatment window, castability, stability and oxidation performance. The alloy employs a balance of refractory elements (Ta, Mo and W) for creep-rupture strength; $\mathrm{Cr}$ and $\mathrm{Co}$ adjustments for stability; and high Ta for castability. Al, Ti and Ta content targets $\sim 70 \%$ volume fraction $\gamma^{\prime}$ phase; and high $\mathrm{Al}$, low Mo plus small Hf addition results in good bare oxidation resistance and coating adherence. The density of CMSX-7 alloy is approximately $8.8 \mathrm{~g} / \mathrm{cm}^{3}$. DSC solidus and liquidus are $1325^{\circ} \mathrm{C}$ and $1381^{\circ} \mathrm{C}$, respectively.

A multi-step solution heat treatment and double age cycle produces complete $\gamma^{\prime}$ solutioning with some remnant $\gamma / \gamma^{\prime}$ eutectic, no incipient melting and $\sim 0.5 \mu \mathrm{m}$ average cubic aligned $\gamma^{\prime}$ phase indicting appropriate mismatch and interfacial chemistry (Fig. 15).

\subsection{Mechanical properties}

Mechanical property characterization of CMSX-7 alloy includes creep- and stress-rupture testing across a matrix of temperature/stress conditions and strain-controlled low cycle fatigue testing. Larson-Miller rupture life of CMSX-7 alloy compared to CMSX-2/3 demonstrates improved properties to $\sim 1038{ }^{\circ} \mathrm{C}$ and similar properties above (Fig. 16) [8]. Surprisingly, CMSX-7 alloy 

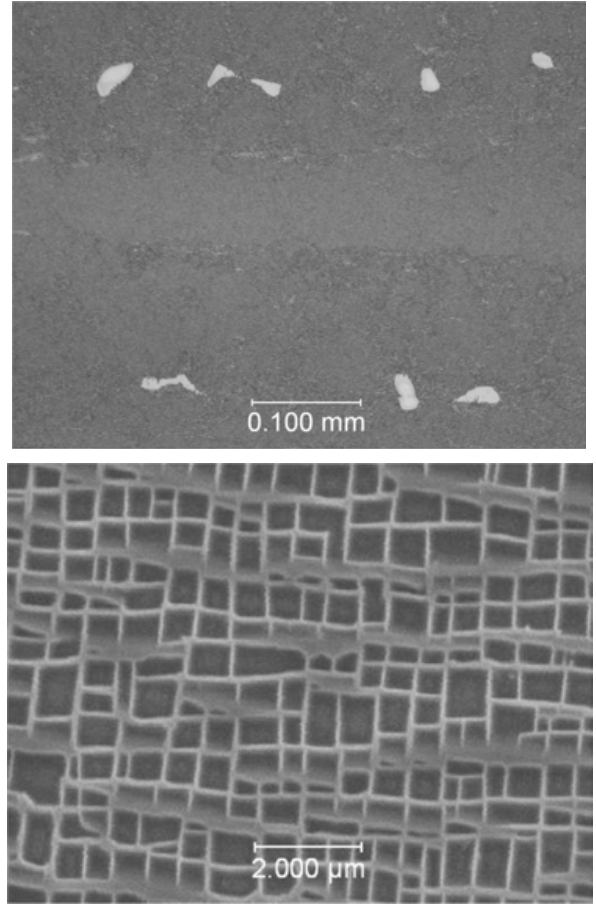

Figure 15. CMSX-7 casting microstructure following solution + double age heat treatment.

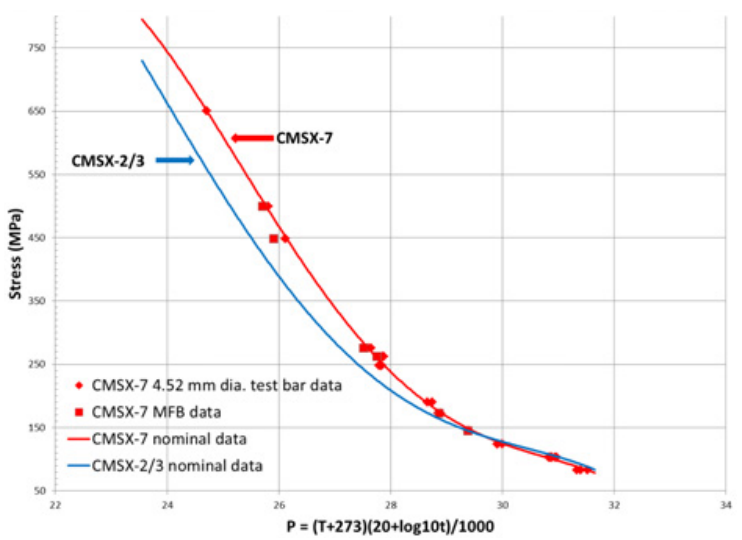

Figure 16. Larson-Miller rupture life of CMSX-7 vs. CMSX-2/3.

rupture life is similar to Rene' N5/N515 alloy data despite the absence of $\mathrm{Re}$ in CMSX-7 (Fig. 17) $[1,5,6]$. This improvement in strength is attributed to the significant increase in refractory content, $\mathrm{Ta}+\mathrm{W}+\mathrm{Mo}$ $\sim 18.6 \%$, compared to $14.6 \%$ for CMSX-2/3, $16.5 \%$ for CMSX-4 and $16 \%$ for Rene' N5 alloys. CMSX7 alloy accommodates the higher refractory content through appropriate reduction of $\mathrm{Cr}$ content to mitigate stability problems. This is depicted in post-creep-rupture metallography (Fig. 18), which shows typical rafted microstructure with minimal non-detrimental TCP phase formation.

Results from strain-controlled LCF testing of CMSX-7 alloy are shown in S-N curves at $1038^{\circ} \mathrm{C}$ and $1093{ }^{\circ} \mathrm{C}$ (Fig. 19). Of note, crack initiation data at $1038^{\circ} \mathrm{C}$ is surprisingly good, similar to CMSX-4 data for HIP'ed + heat treated specimens [9].

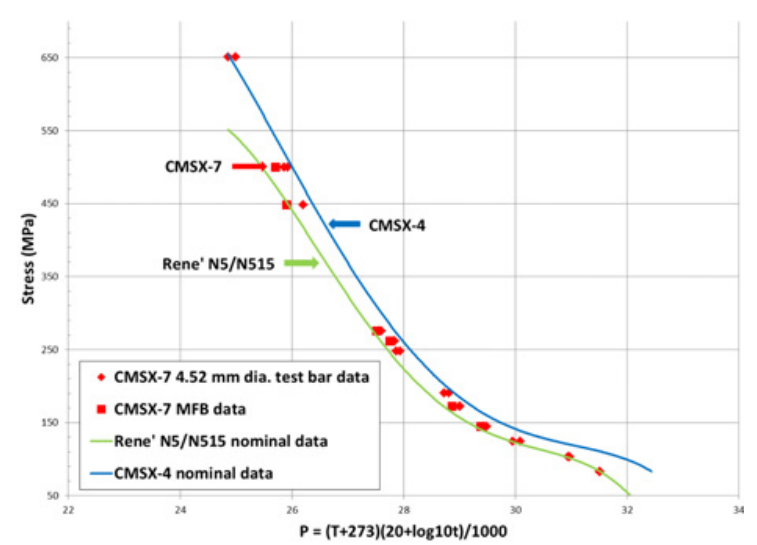

Figure 17. Larson-Miller rupture life of CMSX-7 vs. CMSX-4 and Rene'N5/N515.
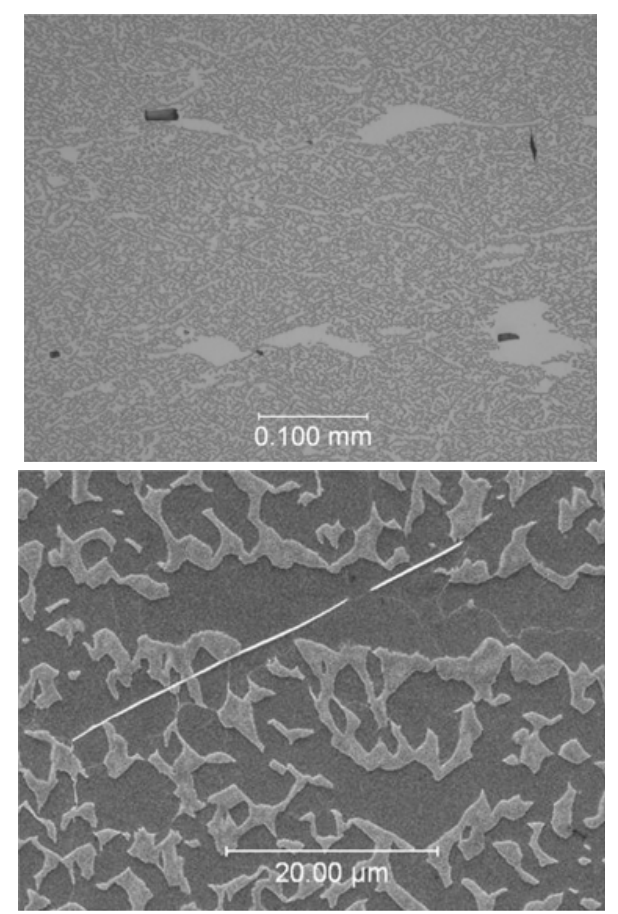

Figure 18. CMSX-7 microstructure following 1176 hours stressrupture testing at $1093^{\circ} \mathrm{C}$.

\subsection{Castability}

SX castability assessments for CMSX-7 alloy have been excellent with $95 \%+$ yield for primary orientation (within $10^{\circ}$ of $\langle 001\rangle$ for seeded casting) and grain defects on test material.

\section{Summary}

Two new single crystal alloys, low Re CMSX-8 and CMSX-7 containing no Re, offer competitive properties to existing commercial SX alloys with lower alloy cost. CMSX-8 alloy is comparable to CMSX4 alloy in terms of creep-and stress-rupture properties to at least $1010^{\circ} \mathrm{C}$ with attractive $\mathrm{LCF}$ performance. CMSX-7 alloy demonstrates improved properties over commercial $1^{\text {st }}$ generation SX alloys and is remarkably competitive with Re-containing alloys Rene' N5/N515. 
CMSX®-7 Low Cycle Fatigue [Strain Controlled]
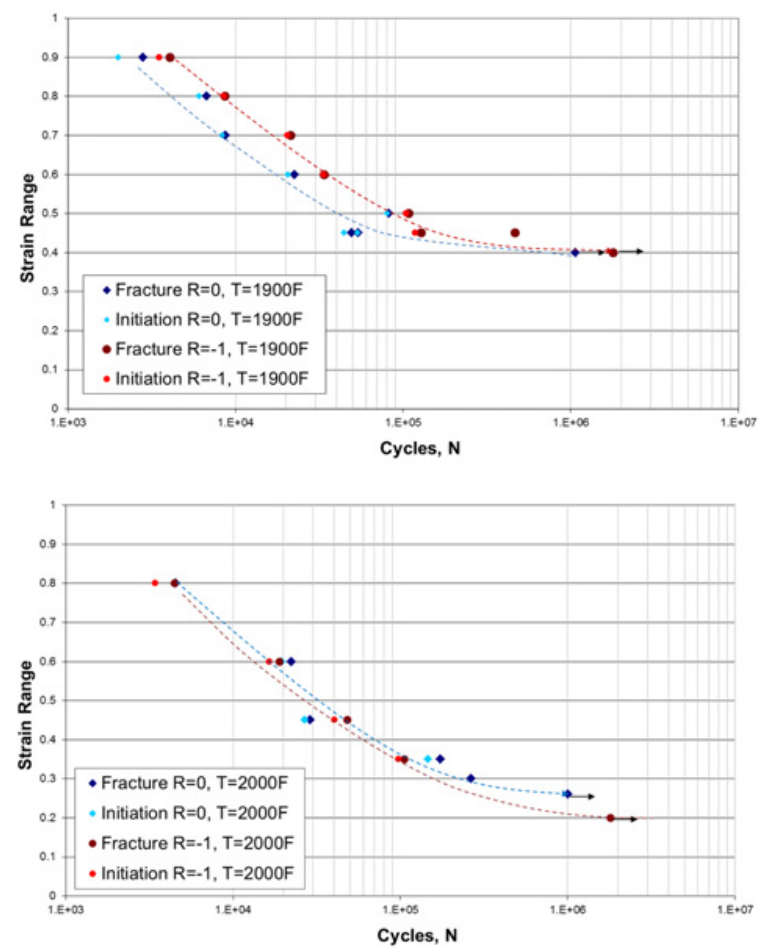

Figure 19. CMSX-7 $1038^{\circ} \mathrm{C}$ and $1093^{\circ} \mathrm{C}$ LCF data.

Both alloys have demonstrated excellent castability and phase stability. Alloy modifications for enhanced oxidation resistance/TBC life and improved grain defect accommodation for large and/or complex castings are also available.

\section{References}

[1] D.J. Frasier, et al., "Process and Alloy Optimization for CMSX-4 ${ }^{\circledR}$ Superalloy Single Crystal Airfoils," (Cost 501/505 High Temp Materials for Power Eng 1990 Conf., Liege, Belgium, September, 1990)

[2] J.H. Zhang, et al., "Interfacial Dislocation Networks Strengthening a 4th-Generation SX TMS-138 Superalloy," Met Trans A, 33A, 3741-3746 (2002)

[3] R.W. Broomfield, "Development and Turbine Engine Performance of Three Advanced Rhenium Containing Superalloys for Single Crystal and Directionally Solidified Blades and Vanes," (ASME-IGTI) 97-GT117

[4] J.B. Wahl, and K. Harris, "New Single Crystal Superalloys, CMSX ${ }^{\circledR}-7$ and CMSX ${ }^{\circledR}-8$," Superalloys 2012, 179-188 (2012)

[5] P.J. Fink, J.L. Miller, and D.G. Konitzer, "Rhenium Reduction - Alloy Design Using an Economically Strategic Element," JOM, 62 No. 1 55-57 (Jan. 2010)

[6] W.S. Walston, et al., "Rene' N6: Third Generation Single Crystal Superalloy," Superalloys 1996, 27-34 (1996)

[7] E.W. Ross, and K.S. O'Hara, "Rene' N4: A First Generation Single Crystal Turbine Airfoil Alloy with Improved Oxidation Resistance Low Angle Boundary Strength,"Superalloys 1996, 19-25 (1996)

[8] K. Harris, G.L. Erickson, and R.E. Schwer, "CMSX ${ }^{\circledR}$ Single Crystal, CM DS \& Integral Wheel Alloys Properties \& Performance," (Cost 50/501 Conference "High Temperature Alloys for Gas Turbines \& Other Applications", Liege, Belgium, October, 1986)

[9] Sun, E., private communication with authors, RollsRoyce Corporation, 1 February 2012 